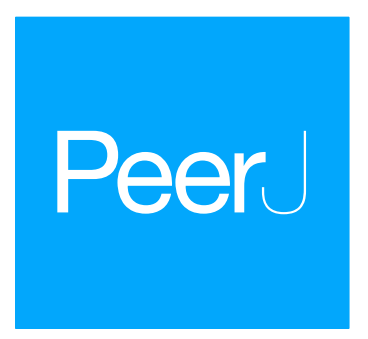

Submitted 24 April 2020

Accepted 7 December 2020

Published 15 January 2021

Corresponding author

Aziza Merzouki,

FatmaAziza.Merzouki@unige.ch

Academic editor

Jason Blackburn

Additional Information and Declarations can be found on page 13

DOI 10.7717/peerj.10660

Copyright

2021 Merzouki et al.

Distributed under

Creative Commons CC-BY 4.0

\section{Clusters of sub-Saharan African countries based on sociobehavioural characteristics and associated HIV incidence}

\author{
Aziza Merzouki ${ }^{1}$, Janne Estillil ${ }^{1,2}$, Erol Orel ${ }^{1}$, Kali Tal ${ }^{3}$ and Olivia Keiser ${ }^{1}$ \\ ${ }^{1}$ Institute of Global Health, University of Geneva, Geneva, Switzerland \\ ${ }^{2}$ Institute of Mathematical Statistics and Actuarial Science, University of Bern, Bern, Switzerland \\ ${ }^{3}$ Institute of Primary Health Care (BIHAM), University of Bern, Bern, Switzerland
}

\section{ABSTRACT}

Introduction. HIV incidence varies widely between sub-Saharan African (SSA) countries. This variation coincides with a substantial sociobehavioural heterogeneity, which complicates the design of effective interventions. In this study, we investigated how sociobehavioural heterogeneity in sub-Saharan Africa could account for the variance of HIV incidence between countries.

Methods. We analysed aggregated data, at the national-level, from the most recent Demographic and Health Surveys of 29 SSA countries (2010-2017), which included 594,644 persons (183,310 men and 411,334 women). We preselected 48 demographic, socio-economic, behavioural and HIV-related attributes to describe each country. We used Principal Component Analysis to visualize sociobehavioural similarity between countries, and to identify the variables that accounted for most sociobehavioural variance in SSA. We used hierarchical clustering to identify groups of countries with similar sociobehavioural profiles, and we compared the distribution of HIV incidence (estimates from UNAIDS) and sociobehavioural variables within each cluster.

Results. The most important characteristics, which explained 69\% of sociobehavioural variance across SSA among the variables we assessed were: religion; male circumcision; number of sexual partners; literacy; uptake of HIV testing; women's empowerment; accepting attitude toward people living with HIV/AIDS; rurality; ART coverage; and, knowledge about AIDS. Our model revealed three groups of countries, each with characteristic sociobehavioural profiles. HIV incidence was mostly similar within each cluster and different between clusters (median (IQR); 0.5/1000 (0.6/1000), 1.8/1000 $(1.3 / 1000)$ and 5.0/1000 (4.2/1000)).

Conclusions. Our findings suggest that the combination of sociobehavioural factors play a key role in determining the course of the HIV epidemic, and that similar techniques can help to predict the effects of behavioural change on the HIV epidemic and to design targeted interventions to impede HIV transmission in SSA.

Subjects HIV, Infectious Diseases, Computational Science

Keywords HIV incidence, Sociobehavioural characteristics, Unsupervised machine learning, Dimensionality reduction, Hierarchical clustering, Principal component analysis

OPEN ACCESS 


\section{INTRODUCTION}

The burden of HIV in sub-Saharan Africa (SSA) is the heaviest in the world; in 2017, $70 \%$ of HIV-infected people lived in this region (UNAIDS, 2018b). However, HIV prevalence and incidence vary widely between SSA countries. The region is heterogeneous and sociobehavioural and cultural factors vary widely within and between countries, complicating the design of effective interventions. This heterogeneity ensures that no "onesize-fits-all" approach will stop the epidemic. This is why the World Health Organization (World Health Organization, 2016) highlights the need to use data and numerical methods to tailor interventions to specific populations and countries based on quantitative evidence.

So far, studies of HIV risk factors or risk factors for the uptake of interventions against HIV have generally been limited to specific sub-populations (Sangowawa \& Owoaje, 2012; Kidman \& Anglewicz, 2016; Ashaba et al., 2018), sub-national regions (Bailey et al., 2007; Gray et al., 2007; Eaton et al., 2014; Pons-Duran et al., 2016) or single countries (Antelman et al., 2007; Gregson et al., 2010; Tsai \& Venkataramani, 2015; Lakew, Benedict \& Haile, 2015; Kelly, Weiser \& Tsai, 2016; Smith Fawzi et al., 2016; Kim, Skordis-Worrall \& Haghparast-Bidgoli, 2016; McGillen et al., 2018; Merzouki et al., 2020). Recent studies included up to 31 SSA countries, but narrowly focused their inquiries to examine, for example, the association between socioeconomic inequalities (Hajizadeh et al., 2014), high-risk sexual behaviour (Kenyon, Buyze \& Schwartz, 2018), or HIV-related stigma (Chan \& Tsai, 2015; Kelly, Weiser \& Tsai, 2016) with HIV testing, treatment uptake, ART (antiretroviral treatment) adherence, or HIV prevalence. Most used standard statistical methods like descriptive statistics (Sangowawa \& Owoaje, 2012; Smith Fawzi et al., 2016), linear or logistic regression (Mondal \& Shitan, 2013; Delavande, Sampaio \& Sood, 2014; Chan \& Tsai, 2015; Kidman \& Anglewicz, 2016; Ashaba et al., 2018), or concentration indices (Hajizadeh et al., 2014; Pons-Duran et al., 2016; Kim, Skordis-Worrall $\&$ Haghparast-Bidgoli, 2016), to assess health inequity and the impact of a small number of variables (five to 13) on the HIV epidemic. In a previous work, we also investigated the associations and possible causal relationships between sociobehavioural factors at the individual-level that are potentially related to the risk of acquiring HIV in 29 SSA countries using Bayesian Network models (Baranczuk et al., 2019). However, these methods do not inform us on how HIV risk factors vary across SSA and which characteristic sociobehavioural patterns at the country-level are actually associated with different rates of new HIV infections in the region.

Recent studies have shown that unsupervised learning and clustering analysis allows us to find hidden sub-groups of people with varying drivers and potentially different risk levels of having or acquiring HIV (Engl, Smittenaar \& Sgaier, 2019; Merzouki et al., 2020). At the country-level, comparing and characterising SSA countries would allow us to test the hypothesis that sociobehavioural heterogeneity might account for spatial variance of HIV epidemic, and inform effective country-specific interventions.

In this study, we used dimensionality reduction and unsupervised machine learning techniques (Principal Component Analysis and hierarchical clustering) to identify the most important factors of 48 national attributes that might account for the variability of 
HIV incidence across SSA, and identified the sociobehavioural profiles that characterized different levels of HIV incidence, based on Demographic and Health Survey (USAID, 2019) data from 29 SSA countries that were aggregated at the national-level.

\section{METHODS}

\section{Data}

We used aggregated data from the most recent Demographic and Health Surveys (DHS) of 29 SSA countries completed between 2010 and 2017, that were available up to July 2018 (Table S1). DHS typically gathers nationally representative (USAID, 2020b) data on health (including HIV-related data) and population (including social, behavioural, geographic and economic data) every 5 years. These data are publicly accessible at the individual-, district- and country-level. We used data aggregated at the national-level.

We attempted to include in our analysis all variables possibly influencing the risks of HIV acquisition among population aged 15-49 years that were available for the 29 SSA countries through the StatCompiler tool (USAID, 2020a). We only included variables that varied significantly across the region, and did not strongly correlate with other variables. We finally pre-selected the following variables: age (under 25 vs older); rurality (rural vs urban); religion (Christian, Muslim, Folk/Popular religions, unaffiliated, others); marital status (married or in union vs widowed/divorced/other), number of wives for men $(1, \geq 2)$ or co-wives for women $(0,1, \geq 2)$; literacy (literate vs illiterate); media access (with access to newspaper, television and radio at least once a week vs without such access); employment (worked in the last 12 months and currently working vs others); wealth (Gini coefficient); age at first sexual intercourse (first sexual intercourse by age 15 vs older); general fertility (number of births to women of reproductive age in the last 3 years); contraception use (using any method of contraception vs not using any); condom use (belief that a woman is justified in asking condom use if she knows her husband has a Sexually Transmitted Infection (STI) vs belief that she is not justified); number of sexual partners in lifetime; unprotected higher risk sex (men who had sex with a non-marital, non-cohabiting partner in the last 12 months and did not use condom during last sexual intercourse vs not); paid sex (men who ever paid for sexual intercourse vs never paid for sex); unprotected paid sex (men who used condom during the last paid sexual intercourse in the last 12 months vs did not use condom); gender-based violence (wife beating justified for at least one specific reason vs not justified for any reason); married women participation to decision making (yes vs no); gender of household head (female vs male); comprehensive correct knowledge about AIDS (yes vs no); HIV testing (ever receiving an HIV test vs never tested); male circumcision (yes vs no); ART coverage (i.e., percentage of people on antiretroviral treatment among those living with HIV); and accepting attitudes toward people living with HIV/AIDS (would buy fresh vegetables from a shopkeeper with AIDS vs would not); see Table 1 for a complete summary of the variables.

We represented each country using 48 dimensions. Each dimension corresponded to an attribute in Table 1, such as the percentage of women married or in union, the mean number of sexual partners in a lifetime for men, the percentage of Christian populations 
and the Gini coefficient in this country. Data were represented as percentages; the mean number of sexual partners in lifetime was scaled using min-max normalisation. Most of these country-level data were exported from the DHS with the StatCompiler tool, except for data on religion that we obtained from Pew-Templeton Global Religious Futures Project (Pew-Templeton Global Religious Futures Project, 2019), and ART coverage that we obtained from UNAIDS' AIDSinfo (UNAIDS, 2019). We used the latest (2018) UNAIDS estimates of national HIV incidence for the year 2016 (UNAIDS, 2019; UNAIDS, 2018a).

\section{Ethics approval}

The study was conducted using aggregated data that are publicly accessible through StatCompiler (for DHS data), Pew-Templeton Global Religious Futures Project, and UNAIDS' AIDSinfo. No ethics approval was needed from our side.

\section{Analysis}

We used Principal Component Analysis (PCA) (Hastie, Tibshirani \& Friedman, 2009; James et al., 2013) to reduce the dimensionality of data from 48 to two dimensions (2D) so we could visualise sociobehavioural similarity between SSA countries. PCA allows to extract directions, called principal components (PCs), along which the variation of data is maximal. The first two PCs, which explain the most variance, represent the axes of the 2D-space used for visualisation. Countries closest to each other when projected on the $2 \mathrm{D}$-space correspond to similar countries in terms of demographic, socioeconomic and behavioural characteristics. PCs consist of a linear combination of the initial 48 dimensions and can therefore be interpreted in terms of the original sociobehavioural variables (STHDA, 2020). We can then identify the variables among those we included in the analysis, that explain most of the sociobehavioural heterogeneity across SSA.

We identified groups of similar SSA countries in terms of sociobehavioural characteristics using hierarchical clustering. Pairwise country dissimilarity was calculated using the Euclidian distance (Equation S1). These distances were used by the hierarchical clustering algorithm to create a dendrogram with 29 terminal nodes representing the countries to be grouped. Cutting the dendrogram at a certain height produces clusters of similar countries. The number of clusters depends on the height at which the tree is cut. We measured the quality of the clustering results using the Silhouette Index, and selected the optimal number of clusters such that it maximised this index (Equation S4).

We compared the HIV incidence of countries between the identified clusters, and visualised the distribution of HIV incidence within each cluster using box plots. We also identified the sociobehavioural variables that characterized the resulting clusters, and visualized the distribution of these variables within each cluster using density plots.

We used the open source $\mathrm{R}$ language, version 3.5.1 for our analysis. Code and country-level data are available on GitLab (https://gitlab.com/AzizaM/dhs_ssa_countries_ clustering), in two separate folders "code" and "data_countries", respectively.

\section{RESULTS}

We analysed aggregated data from surveys that included 594,644 persons in total,183,310 men and 411,334 women (USAID, 2020), ranging from 9,552 in Lesotho to 56,307 in 
Nigeria. Adult HIV incidence ranged from $0.14 / 1000$ in Niger to 19.7/1000 in Lesotho in 2016. HIV prevalence ranged from $0.4 \%$ in Niger to $23.9 \%$ in Lesotho (Table S1). Sociobehavioural characteristics varied widely between SSA countries (Table 1).

\section{Visualizing the SSA countries: Geographical and sociobehavioural similarities}

Using PCA, we found that the first principal component (PC) explained $49.5 \%$ and the second $19.5 \%$ of the total sociobehavioural variance across SSA among the 48 variables we considered (Fig. 1). The original sociobehavioural variables that contributed most to these PCs were religion (12.6\% for Muslim and $12.1 \%$ for Christian populations), male circumcision (9.4\%), number of sexual partners (7.8\% for men and $3.4 \%$ for women), literacy (6.1\% for women and 3.2\% for men), HIV testing (5.5\% for men and 5.4\% for women), women's participation in decision making (3.8\%), an accepting attitude towards those living with HIV/AIDS (3.6\% for women and 3.2\% for men), rurality (3.0\% for women and $2.7 \%$ for men), ART coverage (2.5\%), and women's knowledge about AIDS (2.5\%) (Fig. 1B and Fig. S1).

Projecting the 29 SSA countries in two dimensions produced a roughly V-shaped scatterplot (Fig. 1A). Figure 1B shows how the 48 original sociobehavioural variables vary over the 2D-space. At the end of the V-shape's left branch, Eastern and Southern African countries, such as Namibia, Zimbabwe, Malawi, Zambia and Uganda, lied next to each other. In these countries, fewer men are circumcised, but the percentage of literate people who had accepting attitudes toward people living with HIV/AIDS (PLWHA) was higher and so was the uptake of HIV testing. Knowledge about AIDS and ART coverage were also high. The end of the right branch, in the upper right quadrant, included countries from the Sahel region, like Senegal, Burkina Faso, Mali, Niger and Chad, where the percentage of Muslims is higher and people have fewer sexual partners. The lower tip of the V-shape included countries from West and Central Africa, like Liberia, Ghana, Côte d'Ivoire, Democratic Republic of the Congo, and Gabon, where people have more sexual partners, more men are circumcised, and the population is less rural.

\section{Clustering the SSA countries and analysis of the associated HIV incidence}

The hierarchical clustering of the 29 SSA countries produced a dendrogram (Fig. 2A). Cluster compactness and separation were optimal (maximum silhouette index $=0.3$ ) when we cut the dendrogram at a height that separated countries into three groups (Fig. 2B).

The countries of the first cluster, in yellow, had the lowest HIV incidence (median of $0.5 / 1000$ population) (Fig. 3). This cluster included countries from the Sahel Region, where the population was mostly rural (median of $71.1 \%$ for men) and Muslim (median of $86.2 \%)$. On the one hand, countries of this cluster were characterized by many factors that could account for low HIV incidence and prevalence. Countries were characterized by high proportions of circumcised men (median of 95.0\%), high percentages of women who were married or lived in union (median of 70.6\%), late sexual initiation for men (median of

$1.9 \%$ of men who had their first sexual intercourse by the age of 15), low numbers of sexual 
Table 1 Socioeconomic and behavioural variables included in the analysis.

\begin{tabular}{|c|c|c|c|c|c|}
\hline Attribute & Topic & Variable & Stratification & Categories & Median (min - max) \\
\hline 1 & \multirow{21}{*}{ Demographic } & \multirow{2}{*}{ Age under 25} & Men & & $37.6 \%(28.1 \%-44.1 \%)$ \\
\hline 2 & & & Women & & $39.9 \%(34.4 \%-45.0 \%)$ \\
\hline 3 & & \multirow{2}{*}{ Rurality } & Men & & $56.5 \%(12.9 \%-85.1 \%)$ \\
\hline 4 & & & Women & & $59.7 \%(11.3 \%-89.4 \%)$ \\
\hline 5 & & \multirow{5}{*}{ Religion } & & Christian & $74.9 \%(0.8 \%-97.8 \%)$ \\
\hline 6 & & & & Muslim & $13.9 \%(0.0 \%-98.5 \%)$ \\
\hline 7 & & & & Folk/Popular & $1.7 \%(0.0 \%-35.7 \%)$ \\
\hline 8 & & & & Unaffiliated & $2.5 \%(0.0 \%-18.0 \%)$ \\
\hline 9 & & & & Others & $0.2 \%(0.0 \%-2.7 \%)$ \\
\hline 10 & & \multirow{2}{*}{ Married or in union } & Men & & $50.5 \%(28.8 \%-65.2 \%)$ \\
\hline 11 & & & Women & & $63.5 \%(34.0 \%-88.5 \%)$ \\
\hline 12 & & \multirow{5}{*}{$\begin{array}{l}\text { Number of wives (for men) and co-wives } \\
\text { (for women) }\end{array}$} & \multirow{3}{*}{ Men } & $1^{\mathrm{a}}$ & $87.5 \%(72.0 \%-97.5 \%)$ \\
\hline 13 & & & & $\geq 2^{\mathrm{b}}$ & $12.5 \%(2.5 \%-28.0 \%)$ \\
\hline 14 & & & & $0^{c}$ & $75.5 \%(57.6 \%-93.2 \%)$ \\
\hline 15 & & & \multirow[t]{2}{*}{ Women } & $1^{\mathrm{d}}$ & $17.2 \%(1.9 \%-30.4 \%)$ \\
\hline 16 & & & & $\geq 2^{\mathrm{e}}$ & $4.3 \%(0.4 \%-12.3 \%)$ \\
\hline 17 & & \multicolumn{2}{|l|}{ Female headed household } & & $28.0 \%(9.3 \%-43.9 \%)$ \\
\hline 18 & & \multirow{2}{*}{ Literacy } & Men & & $79.0 \%(37.6 \%-94.2 \%)$ \\
\hline 19 & & & Women & & $58.1 \%(14.0 \%-97.0 \%)$ \\
\hline 20 & & \multirow{2}{*}{ Access to media at least once a week } & Men & & $9.9 \%(1.7 \%-47.5 \%)$ \\
\hline 21 & & & Women & & $5.6 \%(0.3 \%-21.3 \%)$ \\
\hline 22 & \multirow{2}{*}{ Employment } & \multirow{2}{*}{$\begin{array}{l}\text { Worked in the last } 12 \text { months and is } \\
\text { currently working }\end{array}$} & Men & & $76.9 \%$ (55.9\%-92.8\%) \\
\hline 23 & & & Women & & $61.8 \%(24.5 \%-77.8 \%)$ \\
\hline 24 & \multirow[t]{5}{*}{ Wealth } & Gini coefficient $\mathrm{f}^{\mathrm{f}}$ & & & $30.0 \%(10.0 \%-50.0 \%)$ \\
\hline 25 & & \multirow{2}{*}{ First sex by age 15} & Men & & $8.0 \%(0.8 \%-25.4 \%)$ \\
\hline 26 & & & Women & & $18.0 \%(2.6 \%-28.8 \%)$ \\
\hline 27 & & General fertility rate & Women & & $17.5(11.8-26.9)$ \\
\hline 28 & & Use of contraception & Women & & $21.7 \%(5.4 \%-50.2 \%)$ \\
\hline 29 & \multirow{8}{*}{ Sexual behaviour } & \multirow{2}{*}{$\begin{array}{l}\text { Woman is justified asking for condom } \\
\text { if husband has a sexually transmitted } \\
\text { infection (STI) }\end{array}$} & Men & & $88.2 \%(70.3 \%-98.5 \%)$ \\
\hline 30 & & & Women & & $81.5 \%(14.3 \%-97.3 \%)$ \\
\hline 31 & & \multirow{2}{*}{ Mean number of sexual partners in lifetime } & Men & & $6.3(1.9-15.3)$ \\
\hline 32 & & & Women & & $2.2(1.2-5.1)$ \\
\hline 33 & & \multirow{2}{*}{ Unprotected higher risk sex } & Men & & $15.7 \%(1.6 \%-43.2 \%)$ \\
\hline 34 & & & Women & & $11.10 \%(0.3 \%-30.3 \%)$ \\
\hline 35 & & Ever paid for sexual intercourse & Men & & $7.7 \%(1.4 \%-35.0 \%)$ \\
\hline 36 & & Unprotected paid sexual intercourse & Men & & $0.8 \%(0.1 \%-8.1 \%)$ \\
\hline 37 & \multirow{2}{*}{$\begin{array}{l}\text { Gender-based vio- } \\
\text { lence }\end{array}$} & \multirow{2}{*}{ Wife beating justified } & Men & & $32.3 \%(12.5 \%-59.5 \%)$ \\
\hline 38 & & & Women & & $45.7 \%(16.2 \%-76.3 \%)$ \\
\hline 39 & \multirow{2}{*}{$\begin{array}{l}\text { Women empower- } \\
\text { ment }\end{array}$} & \multicolumn{2}{|l|}{$\begin{array}{l}\text { Married women participating in decision } \\
\text { making }\end{array}$} & & $49.9 \%(9.1 \%-78.0 \%)$ \\
\hline 40 & & $\begin{array}{l}\text { Married women who disagree with all } \\
\text { reason justifying wife beating }\end{array}$ & & & $47.7 \%(18.7 \%-80.9 \%)$ \\
\hline
\end{tabular}


Table 1 (continued)

\begin{tabular}{|c|c|c|c|c|c|}
\hline Attribute & Topic & Variable & Stratification & Categories & $\operatorname{Median}(\min -\max )$ \\
\hline 41 & \multirow{6}{*}{ HIV/AIDS } & \multirow{2}{*}{$\begin{array}{l}\text { Comprehensive correct knowledge about } \\
\text { AIDS }\end{array}$} & Men & & $35.8 \%(17.4 \%-68.8 \%)$ \\
\hline 42 & & & Women & & $27.8 \%(10.9 \%-66.9 \%)$ \\
\hline 43 & & \multirow{2}{*}{ Ever received an HIV test } & Men & & $30.5 \%(7.8 \%-80.8 \%)$ \\
\hline 44 & & & Women & & $49.6 \%(14.5 \%-85.5 \%)$ \\
\hline 45 & & Male circumcision & & & $94.0 \%(14.3 \%-99.4 \%)$ \\
\hline 46 & & ART $^{*}$ coverage 2015 & & & $41.0 \%(18.0 \%-76.0 \%)$ \\
\hline 47 & \multirow{2}{*}{$\begin{array}{l}\text { Accepting attitudes } \\
\text { toward PLWHA }\end{array}$} & \multirow{2}{*}{$\begin{array}{l}\text { Would buy vegetables from shopkeeper } \\
\text { with AIDS }\end{array}$} & Men & & $57.5 \%(32.4 \%-92.1 \%)$ \\
\hline 48 & & & Women & & $53.1 \%(23.7 \%-89.2 \%)$ \\
\hline
\end{tabular}

Notes.

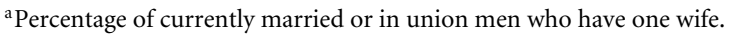

${ }^{b}$ Percentage of currently married or in union men who have two or more wives.

${ }^{c}$ Percentage of currently married or in union women whose husband has no other wives.

${ }^{\mathrm{d}}$ Percentage of currently married or in union women whose husband has one other wife.

ePercentage of currently married or in union women whose husband has two or more wives.

${ }^{\mathrm{f}}$ The Gini coefficient indicates the level of wealth concentration in a country.

${ }^{\mathrm{g}}$ Average number of children currently being born to women of reproductive age in the three years preceding the survey, expressed per 100 women age $15-44$.

${ }^{h}$ Percentage of currently married women age 15-49 who usually make all three specific decisions either alone or jointly with their husband for (1) own health care, (2) large household purchases, and (3) visits to family or relatives.

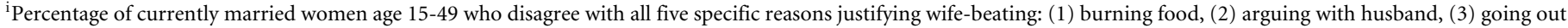
without telling him, (4) refusing sexual intercourse with him and (5) neglecting children.

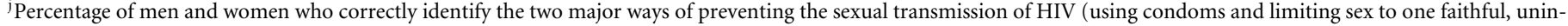

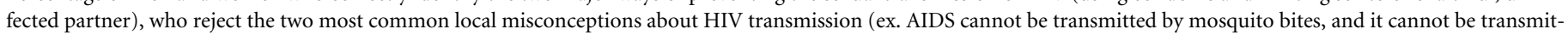
ted by supernatural means), and who know that a healthy-looking person can have HIV.

partners (median of 3.5 partners for men), low percentages of unprotected higher-risk sex (median of $9.7 \%$ for men) and low percentages of men having ever paid for sex (median of 3.9\%). Polygyny (Reniers \& Tfaily, 2012; Eaton et al., 2014), an institutionalized form of sexual concurrency, was also frequent in this region (median of $22.3 \%$ ). On the other hand, this cluster was also characterized by frequent belief that wife beating is justified (median of $61.2 \%$ for women), and low levels of literacy (median of $29.0 \%$ for women). Participation of married women in decision making (median of 18.5\%), contraceptive prevalence (median of 13.9\%), and knowledge about AIDS (median of $23.7 \%$ for women) was also low. These countries had low percentages of people ever tested for HIV (median of $19.2 \%$ for men; $36.6 \%$ for women), low ART coverage (median of 38.0\%) and low levels of acceptance of PLWHA (Median of $47.4 \%$ for men); see Figs. 4 and 5.

The countries of the second cluster, coloured in orange, included countries from West and Central Africa. These countries had a rather low HIV incidence (median of 1.8/1000 population), though Mozambique was a remarkable outlier, with a high HIV incidence (9.8/1000 population) (Fig. 3). Like the first cluster, these countries had a high percentage of circumcised men (median of 97.0\%, except in Mozambique where only 48.4\% of men were circumcised). However, these countries were also characterized by the lowest proportions of rural populations (median of $49.0 \%$ for men), the highest numbers of sexual partners (median of 10.1 for men), early sexual initiation (median of $12.0 \%$ of men who had their first sexual intercourse by the age of 15), and more frequent unprotected high-risk sex (median of $24.3 \%$ for men) and paid sexual intercourse (median of $9.5 \%$ for men). HIV testing uptake (median of $25.8 \%$ for men and $48.6 \%$ for women), knowledge about AIDS (median of $23.6 \%$ for women), and ART coverage (median of $31.0 \%$ ) were all low. 

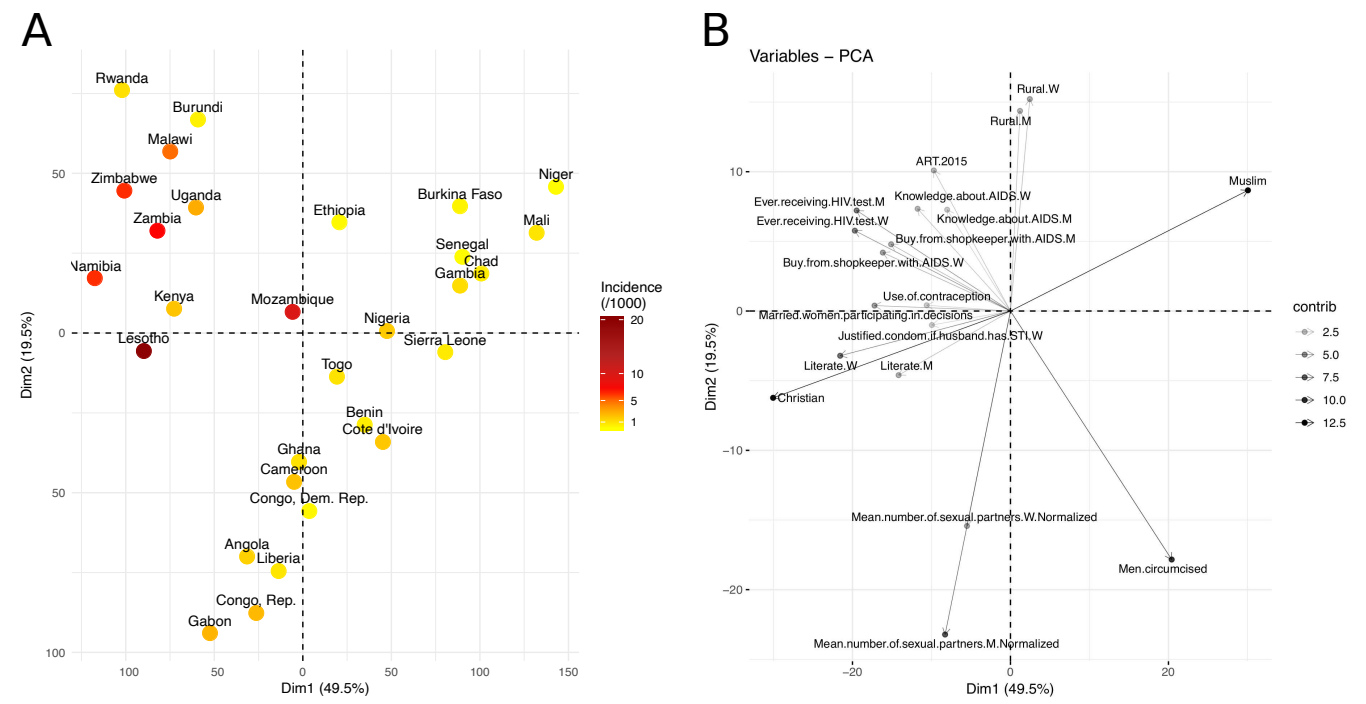

Figure 1 Visualization of the sociobehavioural similarity between SSA countries using PCA. (A) Projection of the SSA countries on a 2D-space, based on their socioeconomic and behavioural factors. The two dimensions (first two PCs), Dim1 and Dim2, explained 69\% of the sociobehavioural variance in the data, given the 48 attributes used in this analysis. Countries are coloured based on their HIV incidence per 1,000 population (15-49) in 2016. (B) Correlation plot of the original variables with the first and second dimensions (Dim1, Dim2). The variable transparency represents its contribution (in \%) to the two dimensions. Moving along a variable's vector leads toward a region of the $2 \mathrm{D}$-space where the variable levels tend to be higher, e.g., upper right quadrant contains mainly Muslim countries, while upper left quadrant contains countries with higher levels of HIV testing and knowledge about AIDS.

Full-size DOI: 10.7717/peerj.10660/fig-1

The third cluster, in red, included Southern and East African countries. These countries had high HIV incidence (median of 5.0/1000 population), except two countries that had a lower HIV incidence: Rwanda (1.1/1000 population) and Burundi (0.5/1000) (Fig. 3). Countries belonging to the third cluster were characterized by the lowest percentage of circumcised men (median of 27.9\%). But they were also the ones with the highest uptake of HIV testing (median of $65.2 \%$ for men; $83.3 \%$ for women) and ART (median of $61.0 \%$ ), and the highest percentage with knowledge about AIDS (median of 54.6\% for women) and accepting attitudes towards PLWHA (median of $84.4 \%$ for men). This cluster was also characterized by the highest percentage of literacy (median of $80.2 \%$ for women), high use of contraceptives (median of $42.6 \%$ ), low percentages of unprotected high-risk sex (median of $9.8 \%$ for men) and higher percentages of married women participating in decision making (median of 67.7\%) and women-headed households (median of 31.0\%). Rwanda and Burundi had the lowest HIV incidence and were characterized by a lower number of sexual partners (Rwanda, 2.6; Burundi, 2.1) vs a median of 6.3 partners for men in the other countries of the third cluster. They also had larger per capita rural populations (Rwanda, $80.4 \%$; Burundi, $89.4 \%$ ) vs a median of $61.3 \%$ for women in the other countries of the same cluster. 
A

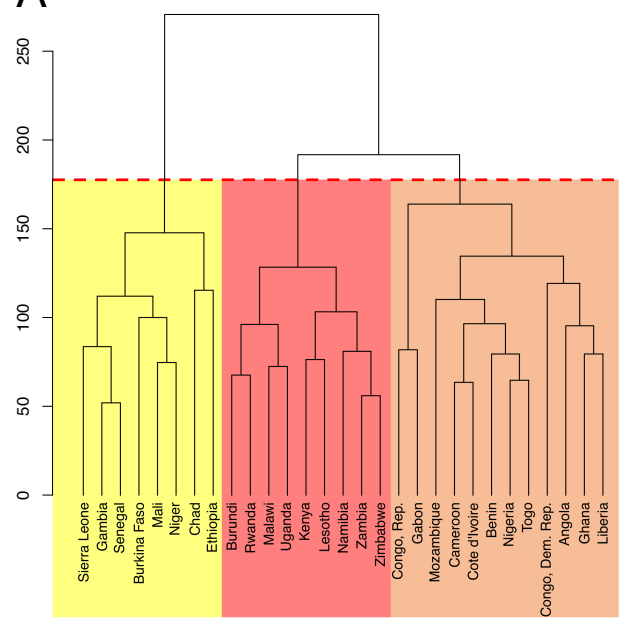

B

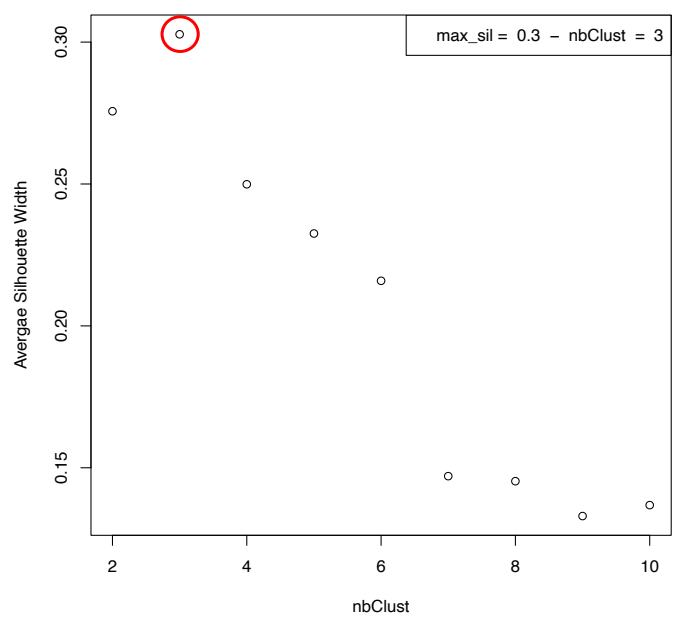

Figure 2 Hierarchical clustering of 29 sub-Saharan African countries. (A) Dendrogram. Cutting the tree at the height of the red dashed line results in three clusters, highlighted in yellow, orange and red. (B) Average Silhouette width for different numbers of clusters. The number of clusters (X axis), from 2 to 10 , corresponds to different heights at which the dendrogram was cut. The maximum average Silhouette width was obtained for three clusters (red circle).

A

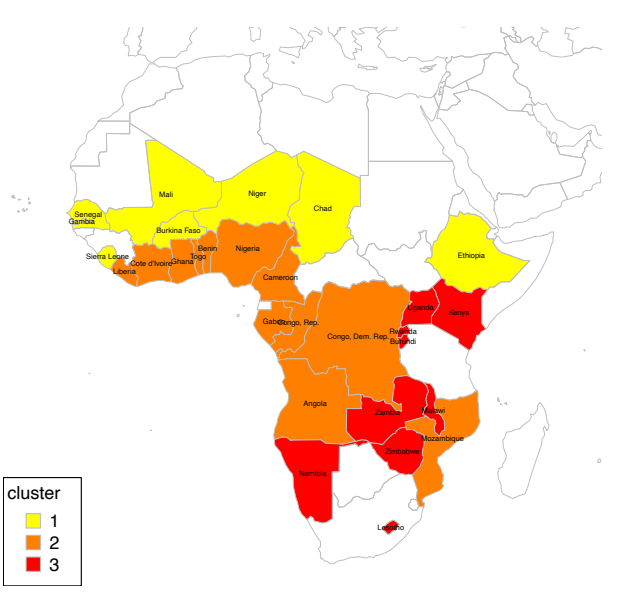

B

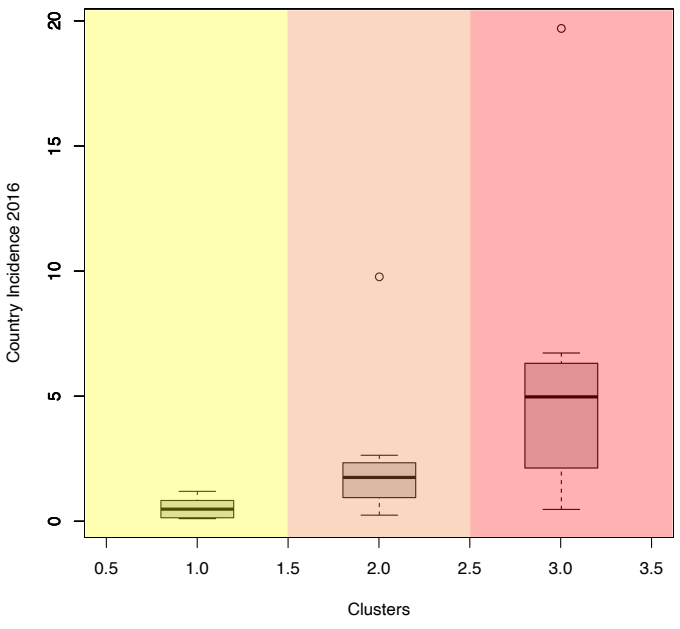

Figure 3 Analysis of the resulting clusters. (A) Map of clustered sub-Saharan African countries. Countries are coloured based on the cluster to which they belong. (B) Box plots of the HIV incidence distribution within each cluster.

Full-size DOI: 10.7717/peerj.10660/fig-3 
A

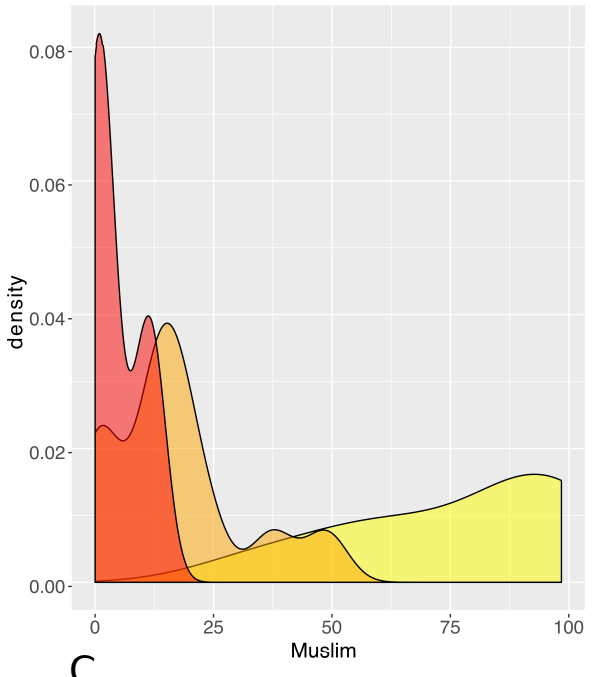

C

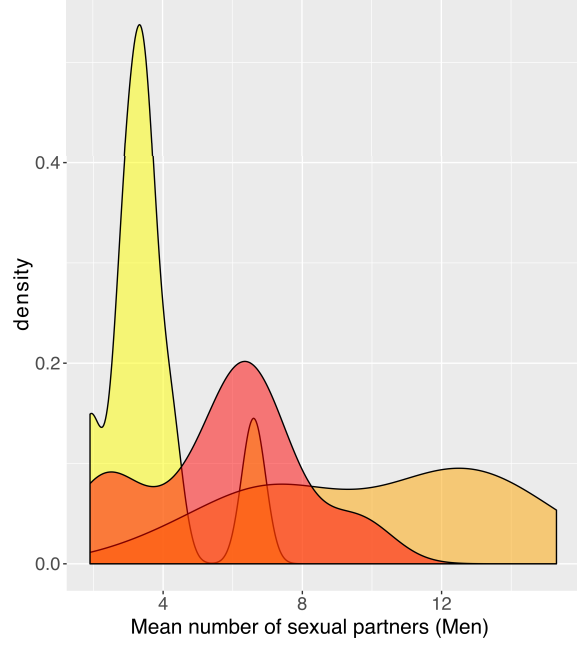

B

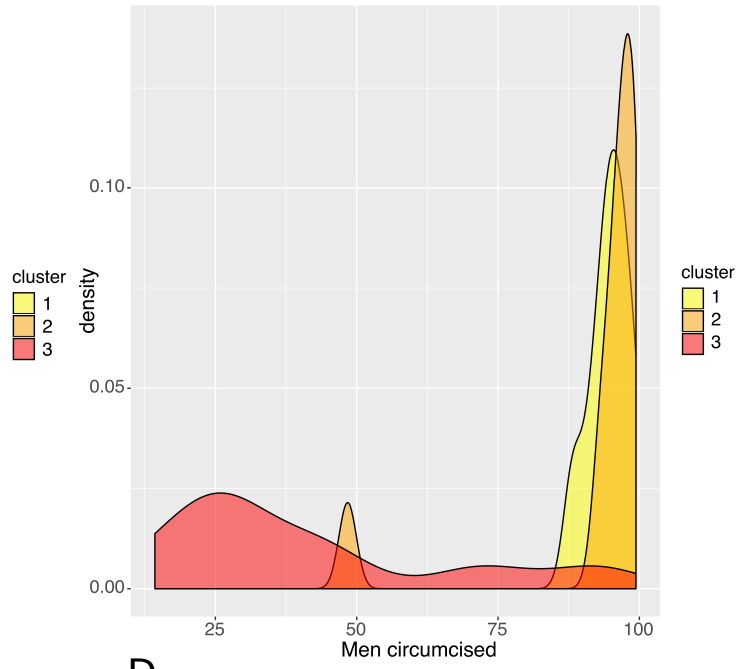

D

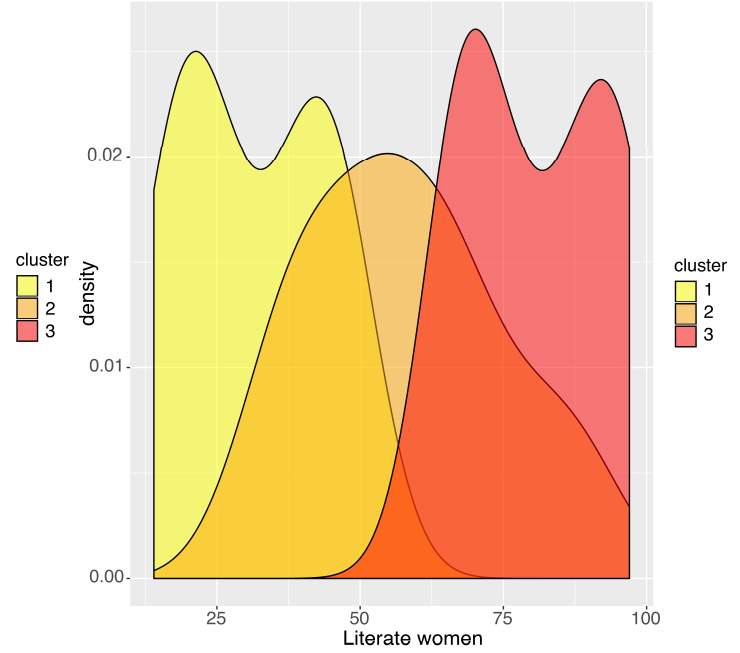

Figure 4 Analysis of the resulting clusters in terms of their sociobehavioural characteristics. Density plots per cluster of (A) the percentage of Muslim population, (B) the percentage of circumcised men, (C) the mean number of sexual partners in a man's lifetime, and (D) the percentage of literate women.

Full-size DOI: 10.7717/peerj.10660/fig-4

\section{DISCUSSION}

Using hierarchical clustering, we identified the most important characteristics that explained $69 \%$ of the sociobehavioural variance among the variables we assessed in SSA. The variables that contributed the most to the sociobehavioural heterogeneity across the 29 SSA countries and among the 48 attributes we included in this analysis are religion, number of sexual partners, literacy, HIV testing, women's participation in decision making, accepting attitude towards those living with HIV/AIDS, rurality, ART coverage, and women's knowledge about AIDS. We found three groups of countries with similar sociobehavioural patterns, and HIV incidence was also similar within each cluster. 
A

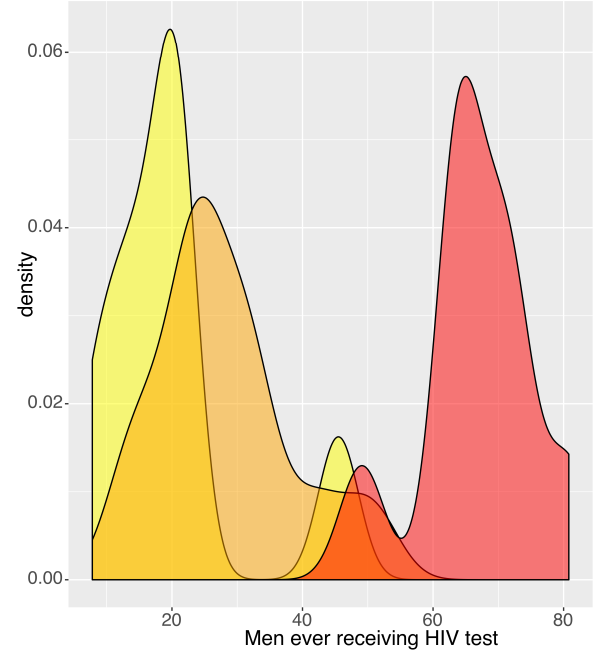

C

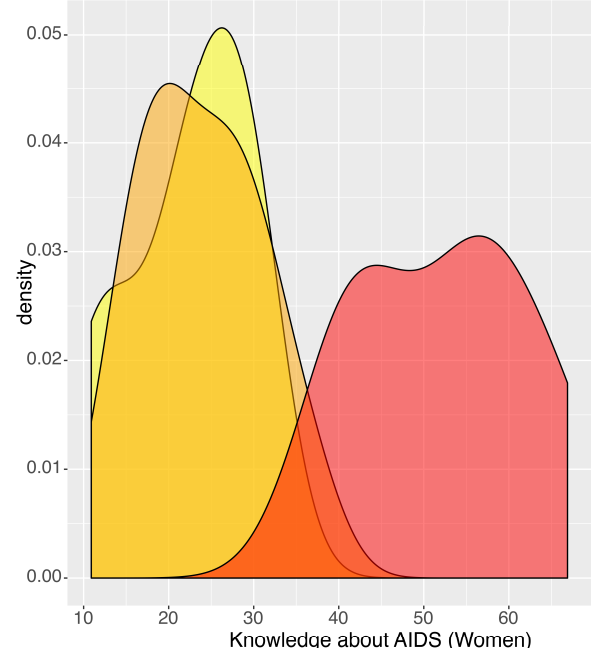

B

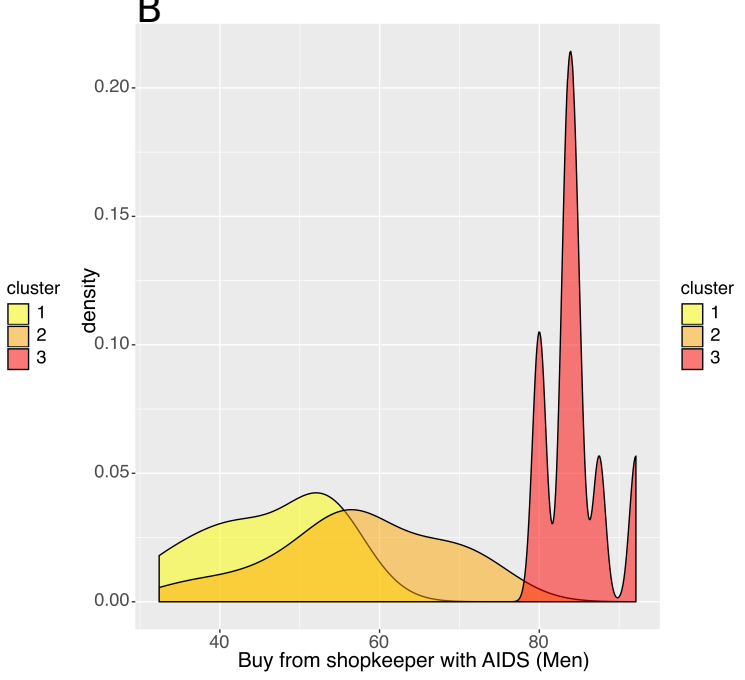

$\mathrm{D}$

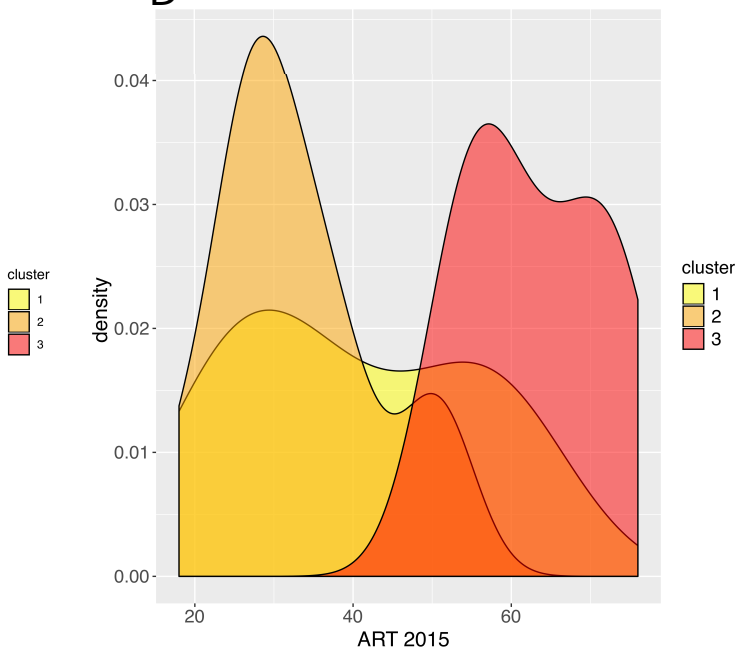

Figure 5 Analysis of the resulting clusters in terms of their HIV-related attributes. Density plots per cluster of (A) the percentage of men who have ever received an HIV test, (B) the percentage of men who say they would buy fresh vegetables from a vendor whom they knew was HIV+, (C) the percentage of women with a comprehensive knowledge about AIDS and (D) the ART coverage in 2015.

In the first cluster, PLWHA were not widely accepted, and the population had an overall low-level knowledge about AIDS. Stigma may be more widespread in this region and explain the lower uptake of interventions among people who are HIV-positive. The relatively low number of people who are living with HIV lowers the general public's exposure to this group and may increase stigma (Chan \& Tsai, 2017). Stigma can also result from cultural and religious beliefs that link HIV/AIDS with sexual transgressions, immorality and sin (Campbell et al., 2005; Mbonu, van den Borne \& De Vries, 2009).

We think that the apparent contradiction between the presence of many high-risk factors and the low HIV incidence in most countries of the second cluster could be explained by the high proportion of circumcised men. In line with this theory, Mozambique, the only 
country in this cluster with very high HIV prevalence and incidence, had few circumcised men. Previous observational studies and trials have confirmed the protective effect of male circumcision (Bailey et al., 2007; Gray et al., 2007; Lei et al., 2015; Sharma et al., 2018).

Countries of the third cluster, with the highest HIV incidence, were also the ones with the highest knowledge about AIDS (Chan \& Tsai, 2017), ART coverage, uptake of HIV testing, and with the most accepting attitudes toward PLWHA. They also had the lowest percentage of unprotected higher risk sex. These findings are consistent with earlier studies that found broad ART coverage may reduce social distancing towards PLWHA and HIV-related stigma in the general population (Chan \& Tsai, 2015; Chan, Tsai \& Siedner, 2015). Reduced social distancing and stigma is associated with higher uptake of voluntary HIV counselling and testing (Kalichman, 2003; Kelly, Weiser \& Tsai, 2016), and less sexual risk-taking among HIV positive people (Delavande, Sampaio \& Sood, 2014).

The high HIV incidence in Mozambique could be caused by any combination of the following factors: a high number of sexual partners; a low level of male circumcision; and a low level of literacy and knowledge about AIDS. The latter two factors can also be responsible for low uptake of HIV testing and ART. However, many West and Central African countries with population characteristics like Mozambique in terms of sexual practices, literacy, knowledge about AIDS, HIV testing and ART coverage, had much lower HIV prevalence and incidence, possibly because males were circumcised at twice the rate. Compared to other West and Central African countries, an aggravating factor in Mozambique can also be the high prevalence of female genital schistosomiasis (Hotez et al., 2019; Yegorov et al., 2019). On the other side of the spectrum, despite a low uptake of male circumcision, it is also possible that the combination of lower numbers of sexual partners, higher per capita rural populations, more literacy, more accurate knowledge about AIDS, more HIV testing, and broader ART coverage could account for lower HIV incidence, like in Rwanda and Burundi.

In contrast to more classical regression techniques that usually estimate the relation between independent sociobehavioural factors and a single outcome, dimensionality reduction and clustering techniques allow us to visualize the sociobehavioural heterogeneity across SSA countries, and identify characteristic patterns of factors that are shared by groups of countries and are found to be associated with different levels of HIV incidence. These results provide policy makers with a quick and clearer overview of sociobehavioural factors across SSA, and help identify targeted interventions that can reduce HIV transmission in a specific country or group of countries.

The cross-sectional nature of our data makes it impossible to determine precedence and causality between the sociobehavioural characteristics we measured and HIV prevalence and incidence. But the associations we identified can open lines of inquiry for researchers. Our study had the advantage of allowing us to compare countries and regions (clusters of countries), but ecological studies that use aggregated data are prone to confounding and ecological fallacy (Levin, 2006). Africa is an exceedingly diverse continent with many distinct sub-populations, so a study based on national population averages cannot explain HIV variation within countries. Recent studies have shown the complex geographical variation of the HIV epidemic and its drivers within Eastern and Southern African countries (Cuadros 
et al., 2017; Bulstra et al., 2020). Therefore, we intend to repeat our study at a lower level of granularity, using regional-, district- and individual-level data to capture differences within countries and learn more about the complex patterns of sociobehavioural factors that affect the sub-populations that are most at risk. We believe that machine learning is a promising innovative way to further explore and improve our understanding of these questions, in parallel to more classical techniques.

Our work has some other limitations. We used model estimates for HIV incidence,[25] which may diverge from reality (Nsanzimana et al., 2017). Sociobehavioural data from the DHS are self-reported, therefore potentially biased; for instance, literate individuals may be more reluctant to admit accepting gender-based violence or having higher risk sex. And even though we included many more variables than is common practice (Hajizadeh et al., 2014; Lakew, Benedict \& Haile, 2015; Kidman \& Anglewicz, 2016; Kim, Skordis-Worrall \& Haghparast-Bidgoli, 2016; Ashaba et al., 2018; Kenyon, Buyze \& Schwartz, 2018), we still had to exclude many factors that can play a critical role in HIV transmission, including the prevalence of excessive alcohol consumption, STIs (Looker et al., 2017; Torrone et al., 2018) (ex. genital herpes, gonorrhea and syphilis), endemic infections (Hotez et al., 2019; Yegorov et al., 2019)(ex. malaria and helminthiases), ART adherence and drug resistance, as well as the distribution of different HIV strains and subtypes (Buonaguro, Tornesello \& Buonaguro, 2007; Esbjörnsson et al., 2019; Gartner et al., 2020). Some of the latter variables were not available from the DHS or were missing for at least one country included in our analysis.

\section{CONCLUSIONS}

Our use of PCA allowed us to identify the most important characteristics among the variables we assessed that explained $69 \%$ of the sociobehavioural variance in SSA countries. With hierarchical clustering, we captured complex patterns of sociobehavioural characteristics shared by countries with similar HIV incidence, suggesting that the combination of sociobehavioural factors plays a key role in determining the course of the HIV epidemic. Our findings can help to design and predict the effect of targeted country-specific interventions to impede HIV transmission.

\section{ACKNOWLEDGEMENTS}

We thank Zofia Baranczuk for helpful discussions.

\section{ADDITIONAL INFORMATION AND DECLARATIONS}

\section{Funding}

This work was supported by the Swiss National Science Foundation [grant no 163878]. The funders had no role in study design, data collection and analysis, decision to publish, or preparation of the manuscript. 


\section{Grant Disclosures}

The following grant information was disclosed by the authors:

Swiss National Science Foundation: 163878.

Competing Interests

The authors declare there are no competing interests.

\section{Author Contributions}

- Aziza Merzouki and Janne Estill conceived and designed the experiments, performed the experiments, analyzed the data, prepared figures and/or tables, authored or reviewed drafts of the paper, and approved the final draft.

- Erol Orel analyzed the data, authored or reviewed drafts of the paper, and approved the final draft.

- Kali Tal and Olivia Keiser conceived and designed the experiments, authored or reviewed drafts of the paper, and approved the final draft.

\section{Data Availability}

The following information was supplied regarding data availability:

Code and country-level data used for this analysis are available on GitLab: https:

//gitlab.com/AzizaM/dhs_ssa_countries_clustering.

\section{Supplemental Information}

Supplemental information for this article can be found online at http://dx.doi.org/10.7717/ peerj.10660\#supplemental-information.

\section{REFERENCES}

\section{Antelman G, Kaaya S, Wei R, Mbwambo J, Msamanga GI, Fawzi WW, Smith Fawzi}

MC. 2007. Depressive symptoms increase risk of hiv disease progression and mortality among women in Tanzania. Journal of Acquired Immune Deficiency Syndromes 44:470-477 DOI 10.1097/QAI.0b013e31802f1318.

Ashaba S, Cooper-Vince C, Maling S, Rukundo GZ, Akena D, Tsai AC. 2018. Internalized HIV stigma, bullying, major depressive disorder, and high-risk suicidality among HIV-positive adolescents in rural Uganda. Global Mental Health 5:e22 DOI 10.1017/gmh.2018.15.

Bailey RC, Moses S, Parker CB, Agot K, Maclean I, Krieger JN, Williams CFM, Campbell RT, Ndinya-Achola JO. 2007. Male circumcision for HIV prevention in young men in Kisumu, Kenya: a randomised controlled trial. The Lancet 369:643-656 DOI 10.1016/S0140-6736(07)60312-2.

Baranczuk Z, Estill J, Blough S, Meier S, Merzouki A, Maathuis MH, Keiser O. 2019. Socio-behavioural characteristics and HIV: findings from a graphical modelling analysis of 29 sub-Saharan African countries. Journal of the International AIDS Society 22:e25437 DOI 10.1101/600510. 
Bulstra CA, Hontelez JAC, Giardina F, Steen R, Nagelkerke NJD, Bärnighausen T, De Vlas SJ. 2020. Mapping and characterising areas with high levels of HIV transmission in sub-Saharan Africa: a geospatial analysis of national survey data. PLOS Medicine 17:e1003042 DOI 10.1371/journal.pmed.1003042.

Buonaguro L, Tornesello ML, Buonaguro FM. 2007. Human immunodeficiency virus type 1 subtype distribution in the worldwide epidemic: pathogenetic and therapeutic implications. Journal of Virology 81:10209-10219 DOI 10.1128/JVI.00872-07.

Campbell C, Foulis CA, Maimane S, Sibiya Z. 2005. I have an evil child at my house: stigma and HIV/AIDS management in a South African Community. American Journal of Public Health 95:808-815 DOI 10.2105/AJPH.2003.037499.

Chan B, Tsai A. 2015. Trends in HIV-related stigma in the general population during the era of antiretroviral treatment expansion: an analysis of 31 Sub-Saharan African Countries. Open Forum Infectious Diseases 2:404 DOI 10.1093/ofid/ofv133.280.

Chan BT, Tsai AC. 2017. Personal contact with HIV-positive persons is associated with reduced HIV-related stigma: cross-sectional analysis of general population surveys from 26 countries in sub-Saharan Africa. Journal of the International AIDS Society 20:21395 DOI 10.7448/IAS.20.1.21395.

Chan BT, Tsai AC, Siedner MJ. 2015. HIV treatment scale-up and HIV-related stigma in Sub-Saharan Africa: a longitudinal cross-country analysis. American Journal of Public Health 105:1581-1587 DOI 10.2105/AJPH.2015.302716.

Cuadros DF, Li J, Branscum AJ, Akullian A, Jia P, Mziray EN, Tanser F. 2017. Mapping the spatial variability of HIV infection in Sub-Saharan Africa: effective information for localized HIV prevention and control. Scientific Reports 7:9093 DOI 10.1038/s41598-017-09464-y.

Delavande A, Sampaio M, Sood N. 2014. HIV-related social intolerance and risky sexual behavior in a high HIV prevalence environment. Social Science \& Medicine 111:84-93 DOI 10.1016/j.socscimed.2014.04.011.

Eaton JW, Takavarasha FR, Schumacher CM, Mugurungi O, Garnett GP, Nyamukapa C, Gregson S. 2014. Trends in concurrency, polygyny, and multiple sex partnerships during a decade of declining HIV prevalence in eastern Zimbabwe. The Journal of Infectious Diseases 210:S562-S568 DOI 10.1093/infdis/jiu415.

Engl E, Smittenaar P, Sgaier SK. 2019. Identifying population segments for effective intervention design and targeting using unsupervised machine learning: an end-toend guide. Gates Open Research 3:1503 DOI 10.12688/gatesopenres.13029.2.

Esbjörnsson J, Månsson F, Kvist A, Da Silva ZJ, Andersson S, Fenyö EM, Isberg P-E, Biague AJ, Lindman J, Palm AA, Rowland-Jones SL, Jansson M, Medstrand P, Norrgren H, N'Buna B, Biague AJ, Biai A, Camara C, Esbjörnsson J, Jansson M, Karlson S, Lindman J, Medstrand P, Månsson F, Norrgren H, Palm AA, Sahin GÖ, Da Silva ZJ, Wilhelmson S. 2019. Long-term follow-up of HIV-2-related AIDS and mortality in Guinea-Bissau: a prospective open cohort study. The Lancet HIV 6:e25e31 DOI 10.1016/S2352-3018(18)30254-6. 
Gartner MJ, Roche M, Churchill MJ, Gorry PR, Flynn JK. 2020. Understanding the mechanisms driving the spread of subtype C HIV-1. EBioMedicine 53:102682 DOI 10.1016/j.ebiom.2020.102682.

Gray RH, Kigozi G, Serwadda D, Makumbi F, Watya S, Nalugoda F, Kiwanuka N, Moulton LH, Chaudhary MA, Chen MZ, Sewankambo NK, Wabwire-Mangen F, Bacon MC, Williams CFM, Opendi P, Reynolds SJ, Laeyendecker O, Quinn TC, Wawer MJ. 2007. Male circumcision for HIV prevention in men in Rakai, Uganda: a randomised trial. The Lancet 369:657-666 DOI 10.1016/S0140-6736(07)60313-4.

Gregson S, Gonese E, Hallett TB, Taruberekera N, Hargrove JW, Lopman B, Corbett EL, Dorrington R, Dube S, Dehne K, Mugurungi O. 2010. HIV decline in Zimbabwe due to reductions in risky sex? Evidence from a comprehensive epidemiological review. International Journal of Epidemiology 39:1311-1323 DOI 10.1093/ije/dyq055.

Hajizadeh M, Sia D, Heymann S, Nandi A. 2014. Socioeconomic inequalities in HIV/AIDS prevalence in sub-Saharan African countries: evidence from the Demographic Health Surveys. International Journal for Equity in Health 13:18 DOI 10.1186/1475-9276-13-18.

Hastie T, Tibshirani R, Friedman J. 2009. The elements of statistical learning: data mining, inference, and prediction. New York: Springer.

Hotez PJ, Harrison W, Fenwick A, Bustinduy AL, Ducker C, Mbabazi PSabina, Engels D, Floerecke Kjetland E. 2019. Female genital schistosomiasis and HIV/AIDS: reversing the neglect of girls and women. PLOS Neglected Tropical Diseases 13:e0007025 DOI 10.1371/journal.pntd.0007025.

James G, Witten D, Hastie T, Tibshirani R. 2013. An introduction to statistical learning: with applications in $R$. New York: Springer.

Kalichman SC. 2003. HIV testing attitudes, AIDS stigma, and voluntary HIV counselling and testing in a black township in Cape Town, South Africa. Sexually Transmitted Infections 79:442-447 DOI 10.1136/sti.79.6.442.

Kelly JD, Weiser SD, Tsai AC. 2016. Proximate context of HIV stigma and its association with HIV testing in sierra leone: a population-based study. AIDS and Behavior 20:65-70 DOI 10.1007/s10461-015-1035-9.

Kenyon C, Buyze J, Schwartz IS. 2018. Strong association between higher-risk sex and HIV prevalence at the regional level: an ecological study of 27 sub-Saharan African countries [version 1; peer review: 2 approved]. F1000Research 7:1879 DOI 10.12688/f1000research.17108.1.

Kidman R, Anglewicz P. 2016. Are adolescent orphans more likely to be HIV-positive? A pooled data analyses across 19 countries in sub-Saharan Africa. Journal of Epidemiology and Community Health 70:791-797 DOI 10.1136/jech-2015-206744.

Kim SW, Skordis-Worrall J, Haghparast-Bidgoli H, Pulkki-Brännström A-M. 2016. Socio-economic inequity in HIV testing in Malawi. Global Health Action 9:1, 31730 DOI 10.3402/gha.v9.31730. 
Lakew Y, Benedict S, Haile D. 2015. Social determinants of HIV infection, hotspot areas and subpopulation groups in Ethiopia: evidence from the National Demographic and Health Survey in 2011. BMJ Open 5:e008669 DOI 10.1136/bmjopen-2015-008669.

Lei JH, Liu LR, Wei Q, Yan SB, Yang L, Song TR, chao, Yuan HC, Lv X, Han P. 2015. Circumcision status and risk of HIV acquisition during heterosexual intercourse for both males and females: a meta-analysis. PLOS ONE 10:e0125436 DOI 10.1371/journal.pone.0125436.

Levin KA. 2006. Study design VI - ecological studies. Evidence-Based Dentistry 7:108 DOI 10.1038/sj.ebd.6400454.

Looker KJ, Elmes JAR, Gottlieb SL, Schiffer JT, Vickerman P, Turner KME, Boily MC. 2017. Effect of HSV-2 infection on subsequent HIV acquisition: an updated systematic review and meta-analysis. The Lancet. Infectious Diseases 17:1303-1316 DOI 10.1016/S1473-3099(17)30405-X.

Mbonu NC, van den Borne B, De Vries NK. 2009. Stigma of people with HIV/AIDS in Sub-Saharan Africa: a literature review. Journal of Tropical Medicine 2009:1-14 DOI 10.1155/2009/145891.

McGillen JB, Stover J, Klein DJ, Xaba S, Ncube G, Mhangara M, Chipendo GN, Taramusi I, Beacroft L, Hallett TB, Odawo P, Manzou R, Korenromp EL. 2018. The emerging health impact of voluntary medical male circumcision in Zimbabwe: an evaluation using three epidemiological models. PLOS ONE 13:e0199453 DOI 10.1371/journal.pone.0199453.

Merzouki A, Styles A, Estill J, Orel E, Baranczuk Z, Petrie K, Keiser O. 2020. Identifying groups of people with similar sociobehavioural characteristics in Malawi to inform HIV interventions: a latent class analysis. Journal of the International AIDS Society 23:e25615 DOI 10.1002/jia2.25615.

Mondal M, Shitan M. 2013. Factors affecting the HIV/AIDS epidemic: an ecological analysis of global data. African Health Sciences 13:301-310 DOI 10.4314/ahs.v13i2.15.

Nsanzimana S, Remera E, Kanters S, Mulindabigwi A, Suthar AB, Uwizihiwe JP, Mwumvaneza M, Mills EJ, Bucher HC. 2017. Household survey of HIV incidence in Rwanda: a national observational cohort study. The Lancet HIV 4:e457-e464 DOI 10.1016/S2352-3018(17)30124-8.

Pons-Duran C, González R, Quintó L, Munguambe K, Tallada J, Naniche D, Sacoor C, Sicuri E. 2016. Association between HIV infection and socio-economic status: evidence from a semirural area of southern Mozambique. Tropical Medicine \& International Health 21:1513-1521 DOI 10.1111/tmi.12789.

Pew-Templeton Global Religious Futures Project. 2019. Religions in Africa. Available at http://www.globalreligiousfutures.org/regions/sub-saharan-africa\#/?region_map_ religion=All Religious Groups (accessed on 24 January 2019).

Reniers G, Tfaily R. 2012. Polygyny, partnership concurrency, and HIV transmission in Sub-Saharan Africa. Demography 49:1075-1101 DOI 10.1007/s13524-012-0114-z.

Sangowawa AO, Owoaje ET. 2012. Experiences of discrimination among youth with HIV/AIDS in Ibadan, Nigeria. Journal of Public Health in Africa 3:e10 DOI 10.4081/jphia.2012.e10. 
Sharma SC, Raison N, Khan S, Shabbir M, Dasgupta P, Ahmed K. 2018. Male circumcision for the prevention of human immunodeficiency virus (HIV) acquisition: a meta-analysis. BJU International 121:515-526 DOI 10.1111/bju.14102.

Smith Fawzi MC, Ng L, Kanyanganzi F, Kirk C, Bizimana J, Cyamatare F, Mushashi C, Kim T, Kayiteshonga Y, Binagwaho A, Betancourt TS. 2016. Mental health and antiretroviral adherence among youth living With HIV in Rwanda. Pediatrics 138:e20153235-e20153235 DOI 10.1542/peds.2015-3235.

STHDA. 2020. PCA principal component analysis essentials articles STHDA. Available at http://www.sthda.com/english/articles/31-principal-component-methods-in-rpractical-guide/112-pca-principal-component-analysis-essentials/ (accessed on 6 January 2020).

Torrone EA, Morrison CS, Chen P-L, Kwok C, Francis SC, Hayes RJ, Looker KJ, McCormack S, McGrath N, Van de Wijgert JHHM, Watson-Jones D, Low N, Gottlieb SL. 2018. Prevalence of sexually transmitted infections and bacterial vaginosis among women in sub-Saharan Africa: an individual participant data meta-analysis of 18 HIV prevention studies. PLOS Medicine 15:e1002511 DOI 10.1371/journal.pmed.1002511.

Tsai AC, Venkataramani AS. 2015. The causal effect of education on HIV stigma in Uganda: evidence from a natural experiment. Social Science \& Medicine 142:37-46 DOI 10.1016/j.socscimed.2015.08.009.

UNAIDS. 2018a. Estimates methods. Available at http:// aidsinfo.unaids.org/documents/ estimates_methods_2018.pdf (accessed on 24 January 2020).

UNAIDS. 2018b. Fact sheet world AIDS day. Available at https://www.unaids.org/sites/ default/files/media_asset/UNAIDS_FactSheet_en.pdf (accessed on 24 January 2020).

UNAIDS. 2019. AIDSinfo. Available at http:// aidsinfo.unaids.org/ (accessed on 6 March 2019).

USAID. 2019. Quality information to plan, monitor and improve population, health, and nutrition programs. The DHS Program. Available at https://dhsprogram.com/ (accessed on 27 September 2019).

USAID. 2020a. STATcompiler. Available at https://www.statcompiler.com/ en/ (accessed on 24 January 2020).

USAID. 2020b. DHS sampling \& household listing manual (English). Available at https:// Ahsprogram.com/publications/publication-dhsm4-dhs-questionnaires-andmanuals.cfm (accessed on 8 October 2020).

World Health Organization. 2016. Global health sector strategy on HIV. Towards ending AIDS. Available at https:// apps.who.int/iris/bitstream/handle/ 10665/246178/ WHO-HIV-2016.05-eng.pdf?.

Yegorov S, Joag V, Galiwango RM, Good SV, Okech B, Kaul R. 2019. Impact of endemic infections on HIV susceptibility in Sub-Saharan Africa. Tropical Diseases, Travel Medicine and Vaccines 5:Article 22 DOI 10.1186/s40794-019-0097-5. 